\title{
CUANDO LA NACIÓN SE ESCRIBE HABLANDO EL CASO DE LA ESCUELA AUDIOVISUAL INFANTIL DE BELÉN DE LOS ANDAQUUEES*
}

\section{WHEN THE NATION IS WRITTEN FROM ORALITY THE CASE OF THE CHILDREN'S AUDIOVISUAL SCHOOL OF BELÉN DE LOS ANDAQUIES}

\section{QUANDO A NAÇ̄̃O SE ESCREVE FALANDO O CASO DA ESCOLA AUDIOVISUAL INFANTIL DE BELÉM DOS ANDAQUIIES}

\section{Páginas Óscar Javier Bermúdez Bolívar \\ 56-69 callejero777@yahoo.com.ar}

Recibido

18 de octubre de 2016

\section{Aceptado}

11 de diciembre de 2016
Comunicador social. Magíster en Literatura de la Universidad Javeriana. Especialista en Comunicación-Educación de la Universidad Central. Su recorrido profesional se ha enfocado en la producción de contenidos sonoros y en el acompañamiento a comunidades en el diseño y ejecución de estrategias de comunicación y de creación de contenidos culturales. Actualmente se desempeña como asesor de la Dirección de Comunicaciones del Ministerio de Cultura. 


\section{Resumen}

La Escuela Audiovisual Infantil de Belén de los Andaquíes es una experiencia de creación de contenidos en la que niños y niñas narran su visión del territorio y relatan su subjetividad desde el lenguaje audiovisual. El presente artículo se acerca a esta experiencia desde una mirada narrativa e intenta descifrar cuáles son las claves que componen su relato, entre ellas la oralidad y su continua apropiación de otros lenguajes y códigos narrativos. Este texto se nutre de argumentos para explicar por qué experiencias como la Escuela Audiovisual Infantil - EAI proponen formas diferentes de reescribir la nación desde las regiones del país. Este artículo se deriva de algunas de las reflexiones surgidas de la tesis de maestría titulada "La oralidad rebelada.

El caso de la Escuela Audiovisual Infantil”, investigación realizada en el marco de la maestría en Literatura de la Universidad Javeriana.

\section{Palabras clave}

Narración, oralidad, apropiaciones, lenguaje audiovisual, Caquetá, Belén de los Andaquíes. 


\section{Abstract}

The Children's Audiovisual School of Belén de los Andaquíes is an experience of content creation in which children narrate their vision of the territory and tell their subjectivity from the audiovisual language. This article approaches the experience from a narrative perspective and intends to decipher the keys that make up its story, including orality and its continued appropriation of other languages and narrative codes. This text draws on arguments to explain why experiences such as the Children's Audiovisual School propose different ways to rewrite the nation from the regions of the country. This article is derived from some of the reflections that emerged from the master's thesis titled "Rebel Orality. The Children's Audiovisual School Case", research carried out within the framework of the master's degree in Literature of the Javeriana University.

\section{Key Words}

Narration, Orality, Appropriations, Audiovisual Language, Caquetá, Belén de los Andaquíes.

\section{Resumo}

A Escola Audiovisual Infantil de Belém dos Andaquíes é uma experiência de criação de conteúdos na que meninos e meninas narram sua visão do território e relatam sua subjetividade desde a linguagem audiovisual. $\mathrm{O}$ presente artigo acerca-se a esta experiência desde uma mirada narrativa e tenta decifrar quais são as chaves que compõem seu relato, entre elas a oralidade e sua contínua apropriação de outras linguagens e códigos narrativos. Este texto nutre-se de argumentos para explicar por que experiências como a Escola Audiovisual Infantil propõem formas diferentes de reescrever a nação desde as regiões do país. Este artigo deriva-se de algumas das reflexões surgidas da tese de mestrado titulada "A oralidad rebelada. O caso da Escola Audiovisual Infantil”, investigação realizada no marco da mestrado em Literatura da Universidade Javeriana.

\section{Palavras-chave}

Narração, oralidad, apropriações, linguagem audiovisual, Caquetá, Belém dos Andaquíes. 
Al amanecer en la finca de mis abuelos empieza el ordeño, amarran los terneros y vacían la leche en otro balde, al terminar el ordeño separan las vacas de los terneros. Mientras tanto, mi tía y mi abuela preparan el desayuno, mientras mi tío lava los marranos. (...) mi abuelito a las siete de la mañana prepara la molienda, muele, enciende el fogón y mi abuelo espera a que hierva el guarapo de caña. (...) al atardecer escuchamos radio y es así como pasamos un día en la finca de mi abuelito. ${ }^{1}$

Maira Yuliana Silva. La finca de mi abuelo.

La narradora del video La finca de mi abuelo es Maira Yuliana Silva, quien, en 2007, tenía unos diez años de edad y convirtió una visita a la finca de su abuelo en un relato audiovisual. Maira es habitante de Belén de los Andaquíes, Caquetá, un municipio encajonado entre la selva y la montaña. Maira es portadora de historias, vaso comunicante de su cultura, narradora de la memoria diaria de su entorno. Ella, como muchos otros niños y jóvenes que integran la Escuela Audiovisual Infantil de Belén de los Andaquíes, es creadora de historias que revelan su cotidianidad.

Esta apuesta de los niños, niñas y jóvenes de la Escuela Audiovisual Infantil (en adelante EAI) por contar su territorio se constituye en una exploración de narrativas alternas y otros discursos donde quepa el mundo que se teje en las regiones más alejadas del país. Esta misión de la EAI se sintoniza con la propuesta del teórico del postcolonialismo Homi Bhabha cuando afirma:

La nación ya no es el signo de la modernidad bajo el cual las diferencias cobran homogeneidad en la visión "horizontal” de la sociedad.

\footnotetext{
1 La metodología usada para la escritura de la presente tesis consiste en un trabajo hermenéutico a partir del cruce de tres variantes o escenarios: primero, la experiencia de la EAI; segundo, las producciones realizadas en el marco de la EAI; y tercero, la teoría que se maneja durante los seis capítulos. Respecto del análisis de las piezas audiovisuales, se llevaron a cabo tres fases. La primera consistió en una aproximación a los videos para hacer un inventario de las mismas, en esta fase se visualizan los 381 videos cortos producidos por la EAI entre noviembre de 2006 y diciembre de 2015 y de ellos se preseleccionaron 50. La segunda fase es de tipo referencial. Se identifican aquí los ejes temáticos, los recursos narrativos y estéticos y se realiza una selección de aquellas piezas audiovisuales en las que la oralidad y la multiplicidad de lenguajes sean más evidentes. Se seleccionan 30 piezas, las cuales se constituyen en el corpus a analizar en la presente tesis. La tercera fase es en un análisis audiovisual aplicado a estas 30 piezas. Esta metodología se origina a partir de los planteamientos del músico Michel Chion, estudioso de la interacción entre imagen y sonido. Chion propone distintas metodologías para acercarse a esta relación, entre ellas la comparación, la cual "consiste en visionar varias veces una secuencia determinada viéndola unas veces con sonido e imagen simultáneamente, otras veces enmascarando la imagen y, otras cortando el sonido" (1990, p. 174). Son preguntas claves de esta metodología ¿Qué veo de lo que oigo? y ¿qué oigo de lo que veo? Este ejercicio, aparentemente simple, permite identificar el rol que juega la oralidad en relación con la imagen y viceversa. Además, sirve para caracterizar el papel que juegan esos distintos recursos narrativos audiovisuales que emplea la EAI en sus videos como fotografías, dibujos de los niños, ilustraciones en pantalla.
} 
La nación revela, en su representación ambivalente y vacilante, la etnografía de su propia historicidad, y abre la posibilidad de otras narrativas del pueblo y su diferencia. (2010, p. 397).

La EAI construye historias que se alejan de los relatos de país propuestos por la prensa regional y nacional y hacen de la cotidianidad, del saber popular $\mathrm{y}$ de las vivencias escenarios donde se teje el relato. Se puede afirmar entonces que la Escuela Audiovisual Infantil está en la búsqueda permanente de distintas formas de reescribir la nación. Descifrar cuáles son estas claves narrativas y cómo ellas contribuyen a escribir de manera distinta la nación implica previamente profundizar en qué consiste la Escuela Audiovisual Infantil.

\section{Qué es la Escuela Audiovisual Infantil}

Mi nombre es José Julián Zambrano Correa, vivo en Belén de los Andaquíes. Comenzamos con un vidrio, con crema, agua. Bueno, eso fue un revoltijo. Después pusimos el dragón y después con mis amigos, con mi hermano comenzamos a poner las cámaras, los ventiladores para poder hacer la película. Después me vine con Alirio para la computadora y Alirio me enseñó a utilizar las voces, los videos, las canciones para ponerle a la película. Estoy muy feliz por hacer esta película con Alirio y con mis amigos.

José Julián Zambrano. El dragón.

La EAI es un colectivo de producción compuesto por niños, jóvenes y adultos que crean relatos sobre el territorio y las gentes de Belén de los Andaquíes en Caquetá. En esta iniciativa de comunicación sus integrantes relatan sus experiencias, ponen en escena su vida familiar, sus intereses, sus preocupaciones y sus vivencias a través de la producción de videos o "películas", como ellos mismos las llaman. Los adultos que lideran este proceso son habitantes de Belén de los Andaquíes, líderes comunitarios y jóvenes comunicadores provenientes casi todos de una experiencia comunicativa anterior ligada a la emisora comunitaria Radio Andaquí. Los niños y adolescentes que hacen parte de la EAI están entre los 10 y los 20 años de edad, la mayoría pertenecen al casco urbano de Belén de los Andaquíes y algunos viven en las veredas más cercanas; la mayor parte son hijos y nietos de migrantes de las últimas oleadas de colonización del departamento de Caquetá y los integrantes más antiguos estudian carreras afines a la producción audiovisual.

La creación de la EAI empezó con la búsqueda de relatos, que por lo general son narraciones orales, sobre lo que los niños perciben, sienten, viven y piensan sobre su universo local. Una de las reglas de la EAI es "Sin historia no hay cámara". Una vez encontrado el relato, sigue la búsqueda de narrativas que le impriman fuerza visual a la historia. Aquí los niños experimentan con diferentes lenguajes y materiales para la puesta en escena. Exploran con ilustraciones hechas por ellos mismos y, por lo tanto, con un marcado rasgo infantil. Además, introducen fotografías de ellos y de su entorno, prueban con personajes hechos con materiales de plastilina, barro, papel, alambre, usan diferentes muñecos y juguetes que son puestos a actuar distintas situaciones relacionadas con la vida cotidiana. Lo que hacen los creadores de la EAI es apelar a la recursividad y descubrir las potencialidades narrativas. Es una especie de reciclaje desde la dimensión narrativa.

La búsqueda de narraciones construidas con la mirada de la gente, el uso del relato oral como elemento transversal, la participación activa de los niños, el uso de diversos lenguajes expresivos y la recursividad en el momento de contar las historias son algunas de las características que definen el sello narrativo de la EAI. Es en estos rasgos donde se pueden encontrar las pistas y las claves sobre cómo la Escuela Audiovisual Infantil busca formas distintas de reescribir la nación. 


\section{La nación: sus temporalidades y narrativas}

Se toman en este punto, algunos planteamientos del teórico del postcolonialismo Homi Bhabha, quien estudia la nación desde su dimensión narrativa. Según Bhabha (2010), la nación está atravesada por dos tipos de temporalidades, una que define como "pedagógica" y la otra como "performativa". (p. 392).

La temporalidad "pedagógica" se relaciona con conceptos como tradición, pueblo, patria, entre otros. Esta se sustenta en la totalidad, en las identidades únicas, en la unicidad política, en la legitimidad que otorga la historia oficial y la homogenización de las culturas. En palabras de Bhabha (2010), lo pedagógico le confiere al discurso una autoridad basada en el origen, en la tradición del pueblo, en la historia vista como una cronología de momentos históricos inmutables Esta temporalidad pedagógica fue la que orientó la consolidación de los Estados, proceso en el cual jugaron un papel importante la escritura y los conocimientos validados por los poderes hegemónicos; eran los letrados quienes regían, desde el escenario de la escritura, el orden en las sociedades (Castro, 1997). Por su parte, Jesús Martín Barbero (2001) considera que la construcción de nación en Colombia se ha dado en medio de dos dinámicas: primero, la ausencia de un relato nacional que construya una mínima trama compartida e integradora de la memoria común de todos los colombianos; y segundo, una violencia de la representación, la cual ha contribuido a excluir a las regiones y deformar la imagen que se construye de las mismas. Violencia de la representación que, a juicio del autor, también se ha dado a través de la homogenización cultural y racial, pues se ha impuesto una sola manera de ser colombiano y se ha sometido a aquellas formas de vida que no tienen cabida dentro esa identidad única.

Este hermanamiento entre la nación, el poder y dispositivos del saber, como la escritura, llevan a
Ingrid Bolívar (2001) a plantearse dos interrogantes: "¿contra qué formas de pensar y ordenar la vida social se construye esta forma nueva de comunidad que se imagina "soberana" y "limitada" (...)? $¿ Q$ Qué otras formas de dominio quedan subsumidas o arropadas bajo esa forma política que es la nación?». (p. 17).

Por otro lado, La temporalidad performativa mira a la nación desde los márgenes. Según Bhabha (2010) esta perspectiva posibilita dirigir la mirada hacia:

Aquellos resquicios de la cultura nacional que fácilmente quedan relegados a las sombras, pero que son altamente significativos, puesto que de ellos pueden emerger movimientos de personas y capacidades analíticas de oposición -la juventud, lo cotidiano, la nostalgia, las nuevas etnicidades, los movimientos sociales, la política de la diferencia-. (p. 14).

Gracias a los procesos desatados por las nuevas tecnologías de la comunicación, proliferan los relatos que revelan los márgenes, que ponen en escena otros sujetos, otras estéticas, otras formas de proyectar la vida, de habitar el territorio y de vivir en los confines.

Es en esta temporalidad performativa donde podríamos ubicar a la Escuela Audiovisual Infantil de Belén de los Andaquíes, pues en sus productos audiovisuales se encuentran otras maneras de escribir la nación, otras narrativas y otros discursos donde haya cabida para el mundo que se teje en los márgenes, esto en sintonía con las propuestas de Homi Bhabha (2010):

Recién cuando la nación occidental aparece ante nuestros ojos, según la famosa frase de Conrad, como uno de los rincones oscuros de la tierra, podemos comenzar a explorar nuevos lugares desde los cuales escribir 
historias de los pueblos y construir teorías de la narración. (p. 17).

Surgen en este punto dos interrogantes: ¿qué hace la EAI para explorar en esas formas distintas de escribir la nación? y ¿cuáles son las claves narrativas que permiten esta búsqueda? Estos son los interrogantes que se intentará resolver y que orientarán el desarrollo del presente artículo.

\section{Primera clave: la oralidad}

Jeisson: todas las mañanas don Andrés va al pueblo a trabajar mientras su esposa se queda cuidando sus cuatro hijos. Maikol: una noche al regresar al pueblo, pilló a su mujer con otro hombre. Jeisson: ella se fue, y a don Andrés le tocó trabajar en el pueblo y en la finca para mantener a sus cuatro hijos. Maikol: don Andrés cansado de trabajar, vendió la finca y se fue para el pueblo con sus hijos.

Jeison Capera y Maikol González. Papá es una madre.

La anterior historia la construyó Jeisson Andrés Capera, que tenía para el 2007 un poco menos de ocho años. Jeisson, al igual que sus otros compañeros, ha aprendido a traducir sus experiencias y las de sus vecinos en historias con inicio, nudo y desenlace. Ellos se han convertido en narradores, cuya materia prima es el relato oral. Todos los videos producidos por la EAI tienen como base la oralidad. Es la palabra hablada el vehículo a través del cual se cuentan las historias sobre el municipio.

Una primera característica de la oralidad en los videos de la EAI es que subyace en ella una carga de resistencia, no tanto desde los mensajes de las piezas audiovisuales, sino desde la posibilidad que permite el relato oral para que circulen los saberes y las miradas del mundo que no han pasado por la escritura.
La historia de Latinoamérica ha estado marcada por la separación radical entre la escritura y la oralidad, la primera cercana a los círculos del poder, y la segunda, relegada a los pueblos y considerada vulgar. Ángel Rama, en su texto La ciudad letrada (1998) hace un recorrido histórico y argumenta que la escritura tenía el rol de reafirmar los poderes hegemónicos y de establecer barreras que separaban la ciudad de los letrados de la ciudad real que se refugiaba en la oralidad

Michel De Certeau, filósofo, teólogo y un estudioso de la cultura de la vida cotidiana, se acerca a la oralidad a partir de su oposición a la escritura, a la ciencia y a los saberes legitimados:

Se define pues por oralidad (o como oralidad) lo que debe distinguirse de una práctica "legítima" -científica, política, escolar, etcétera-. Es "oral” lo que no trabaja en favor del progreso; recíprocamente, es "escriturario" lo que se separa del mundo mágico de las voces y de la tradición. (De Certeau, 2000, p. 118).

Entonces, lo escrito impone un orden jerárquico que ubica en último renglón a la oralidad. Lo escrito se posiciona como el saber socialmente aceptado, verdadero y como el territorio en donde reside lo racional. En ese contexto, la oralidad pasa a ser comprendida como un escenario de resistencia a la escritura, como un espacio táctico para construir y circular esos otros relatos y conocimientos que son excluidos del proyecto escriturario. El hecho de que la EAI tenga como elemento transversal la oralidad y que sean unos niños pertenecientes a una región alejada los creadores de los contenidos, le imprime una carga de resistencia.

Comprender la oralidad como una práctica resistente implica buscar un lugar para lo excluido, darle voz a lo negado, ver los caminos ignorados y despreciados por el saber dominante y la escritura. Esto se traduce en la EAI, pues los videos de 
la EAI ponen en escena los conocimientos desplegados por los niños en sus juegos (Juego de bolas, 2006), describen cómo son los hogares (Mi familia, 2006), exploran los saberes populares de la gente en lo local (La babosa cochosa, 2012), reivindican la importancia de los oficios tradicionales (Serie alta costura, 2012), relatan las estrategias de subsistencia emprendidas por los habitantes del municipio (Pescado fresco, 2007). En ese sentido, es resistencia la oralidad cuando articula unos saberes y unas dinámicas que los conocimientos científicos no comprenden y desprecian.

Este recorrido permite concluir que la EAI escribe la nación desde la oralidad, entendida esta como un espacio táctico que instaura un tejido comunicativo, participativo, sin propietarios y que abre la posibilidad para que los niños, los campesinos, las mujeres de un pueblo como Belén de los Andaquíes construyan narraciones y representaciones de sí mismos. Este relato oral instalado en la cotidianidad convierte a los sujetos anónimos en protagonistas, reconoce sus conocimientos, construye memorias comunes, dota de sentido a las experiencias colectivas y le cuenta al mundo cómo es y quiénes son los habitantes de este municipio de Caquetá.

\section{Segunda clave: los lenguajes de la apropiación}

Yo también fui desplazado de Cartagena del Chairá. Tuve que dejar mis hijos, mis perros y mi maizal (bis). Yo me fui y no sé, pero tengo que volver (bis). La culpa de mi desgracia que hoy me oprime el corazón son las fuerzas nacionales y fuerzas de mi región. No me valió ser honrado, honesto y trabajador (bis). Yo me fui y no sé, pero tengo que volver (bis).

EAI. Yo también fui desplazado

Este relato oral de un desplazado es convertido en una canción de música popular y en un producto audiovisual. La tragedia del personaje es acompañada por las guitarras del grupo Los alegres del Chairá y es convertida en un videoclip por los integrantes de la EAI. En esta pieza comunicativa se puede reflejar el tránsito experimentado por el relato oral cuando se encuentra con los productos de la cultura masiva y con las formas de narrar que tienen los lenguajes mediáticos como el video.

El presente bloque explica cómo la Escuela Audiovisual Infantil escribe de manera diferente la nación a partir de las continuas apropiaciones, mezclas, hibridaciones y préstamos de otros lenguajes y otras formas de narrar. Explicar cómo se producen estas apropiaciones implica en primer lugar comprender las complejas relaciones entre cultura popular y cultura masiva.

En coherencia con el término “apropiación”, la tesis que sirve de base a este artículo se aleja de las separaciones tajantes entre "cultura popular" y "cultura masiva” y plantea más un diálogo entre estas dos formas de cultura. Es por eso por lo que la apuesta es estudiar los cruces entre una y otra, como lo explica la profesora, investigadora y experta en narrativa testimonial Ana María Amar Sánchez (2010): "todos estos enfoques considerados aquí se concentran en las formas de uso, apropiación, hibridez, mediación (...) estos estudios optan por la consideración de los complejos, conflictivos pero muy productivos puntos de intersección, fusión y transformación entre las culturas». (p. 17).

Entonces, en esta relación entre cultura popular y cultura de masas se borran las fronteras entre unas y otras, y la interacción se produce en medio de procesos de lucha, conflicto por la apropiación y el uso entre unas y otras. Las preguntas que surgen aquí son ¿quién apropia a quién?, ¿qué apropia y cómo lo hace? y ¿qué resultados se producen a partir de dicha apropiación? Al respecto, pueden surgir varios caminos: es la élite quien toma los códigos masivos y populares para ponerlos en escena, como lo plantea Amar Sánchez (2010), es la cultura 
de masas y sus industrias del entretenimiento quienes toman las formas de vida, las historias, los personajes, los gustos y las aspiraciones de la cultura popular para construir productos de uso masivo; o son los sujetos de la cultura popular y sus grupos quienes se apropian de los códigos masivos y los incorporan a su mundo cultural.

Dadas las características del proceso de la EAI y su apuesta por la creación de relatos, el camino que resulta más pertinente es el último, pues se enfoca en el terreno de la recepción, en el campo de quiénes reciben los productos de la cultura de masas, y desde allí se apoderan de éstos, los usan, los incorporan a su vida cotidiana y exploran en distintas posibilidades. De acuerdo con Martín Barbero, la relación entre lo popular y lo masivo ha cambiado la pregunta, pues el interrogante ya no es ¿qué le hacen los productos masivos a la gente?, sino ¿qué hace la gente con los productos masivos? Martín Barbero (2003) propone mirar hacia el escenario de «los usos populares de lo masivo, tanto experimentales o rediseño como resemantización». (p. 127). Un ejemplo de esto puede ser el video titulado $E l$ corrido del gordo:

Esta es la historia del gordo, que un día compró una pistola, y entonces a sus amigos les comenzó a disparar. Conmigo nadie se mete, eso lo dice el gordo, saliendo para la tienda a comprar un proveedor. (EAI, 2007).

Este video de la EAI acude al corrido prohibido, apropia su ritmo, pero luego su sentido original es subvertido. Lo que comenzó como una descripción de una escena de violencia propia de este género, «Esta es la historia del gordo, que un día compró una pistola», termina relatando un juego de niños: «si al paseo quieres ir, entregarás la pistola y a todos tus compañeros, disculpas les pedirás». Entonces se toma el corrido prohibido, su ritmo pegajoso, el gusto que genera, la violencia de sus letras, pero luego este es traicionado, su sentido se transforma y ahora le canta a un conflicto cotidiano de niños y a la manera como lo resolvieron pacíficamente y apelando al juego. Esta forma de apropiación la explica Ana María Amar Sánchez (2000) desde el terreno de la literatura en su libro Juegos de seducción y traición.

En conclusión, la nación también se escribe a partir de las continuas apropiaciones, préstamos, copias y fusiones en torno a los productos de la cultura masiva. Estas apropiaciones se producen en el escenario de los géneros y los formatos. Los niños toman las formas de narrar de la industria audiovisual y del entretenimiento y luego las incorporan, las ponen en diálogo con sus procesos de producción, y finalmente utilizan estas técnicas, códigos y estéticas para poner en escena sus vidas, su territorio y sus formas de ver el mundo.

\section{Tercera clave: la oralidad mestiza}

Coro: Vivir en Belén es elegante. Turistas vienen a verte. Coro: Vivir en Belén es elegante. Pescados frescos y sabrosos. Coro: Vivir en Belén es elegante. Árboles gigantes, aguas cristalinas, animales que corren por todas las esquinas (...). De repente todo cambiará. Coro: ya no será bacano vivir por acá. Coro: Ya no será bacano vivir por acá.

EAI. Futuro en Belén de los Andaquíes.

El video titulado Futuro en Belén de los Andaquíes, es una composición colectiva de la EAI, en la cual participaron niños y adultos. En esta pieza audiovisual se encuentra el relato oral como base, el cual es enriquecido con la métrica de una poesía y se vale de la musicalidad para convertirse en rap. En este producto audiovisual el video se convierte en el territorio en donde confluyen múltiples recursos narrativos. La pantalla de video sirve como un lienzo digital habitado por fotografías, ilustraciones, animaciones y textos que se despliegan por la superficie del monitor de video. Se le llama oralidad 
mestiza a este tipo de narración, pues el relato oral se fusiona con múltiples lenguajes expresivos y formas de narrar.

Entonces, la tercera forma de reescribir la nación es a través de la oralidad mestiza, un relato oral hecho de múltiples apropiaciones. El resultado son narraciones en las que el relato oral se fusiona con otros lenguajes como la fotografía, la imagen en movimiento y es narrado a partir de los formatos y productos de la cultura masiva. A continuación, se explica qué es la oralidad mestiza y por qué se considera una forma distinta de escribir la nación. Los niños que integran la EAI son habitantes de la cultura audiovisual, pues han crecido rodeados por la pantalla del televisor, por los computadores, por los equipos móviles, y desde allí se conectan con el mundo, reciben información y conectan sus sensibilidades. En los niños, las niñas y los jóvenes de la EAI conviven los saberes de la oralidad surgidos en la vida diaria y transmitidos por sus padres, con lo efímero, lo inestable, lo plural y lo fragmentario de la cultura audiovisual. Es la oralidad viviendo con la imagen y las nuevas tecnologías. Pedro Cruz, investigador en temas de historia y vanguardias del arte, retoma el concepto de "entre espacios" para referirse a un lugar donde los límites se comprimen pero permanecen relativamente estables, es un espacio común establecido entre los contornos de los territorios. Es por ello por lo que Cruz (2005) considera que el concepto "entre espacios" no es una tierra de nadie sin fuerzas predominantes, sino una zona de contactos.

En el caso de la EAI oralidad, imagen y nuevas tecnologías viven en ese territorio, en ese "entre espacios". Este concepto se traduce en el caso de la EAI en el territorio del video. Visto desde esa perspectiva, el lenguaje audiovisual se convierte en un territorio para la expansión, un espacio donde los diferentes elementos expresivos que allí convergen pierden los límites rígidos y se pasa a un estado de ilimitación como lo plantea Cruz. La pregunta en este punto es ¿qué sucede con el relato oral cuando entra en esta fase de ilimitación?
Narrador 1: Todo empezó cuando los colonos quisieron darle una paliza a los indígenas, es decir, cuando los colonos quisieron derrotar a todos los indígenas.

Narrador 2: ¡Vamos a derrotarlos!

Narrador 1: Los indios no querían ser derrotados. (EAI, 2008).

Este fragmento del video El último andaquí es uno de los mitos fundacionales de Belén de los Andaquíes. A medida que avanza el relato oral de esta pieza audiovisual, el flujo de imágenes recrea al pie de la letra cada una de las acciones descritas por la palabra. El discurso oral en este y en la mayoría de videos de la EAI es el eje articulador de la narración, pues marca el desarrollo narrativo de la historia e indica a la vez la entrada de esos otros lenguajes narrativos como la fotografía y la animación.

Nos valemos en este punto de las reflexiones de Michel Chion, que en su obra La audiovisión. Introducción a un análisis conjunto de la imagen y el sonido, plantea tres modos de presencia de la palabra en el cine: "palabra- teatro", "palabra- emanación” y "palabra- texto". Profundizaremos en este último, "la palabra- texto", pues es la función que más se acerca al manejo dado a la relación entre oralidad e imagen en el caso de los videos de la EAI. De acuerdo con Chion (1990), esta corresponde a la voz en off, son los comentarios que a modo de consciencia hace el narrador, con lo cual orienta el curso de las imágenes, evoca la forma de las cosas, de los momentos y de los personajes.

Así, entonces, se podría afirmar que en el caso de los videos de la EAI es la palabra hablada la que predomina, con lo cual los elementos propios del lenguaje audiovisual son sus subsidiarios y pierden autonomía, como lo explica Chion (1990): «si la palabra- texto reina sin limitaciones, ya no hay autonomía de la escena audiovisual ni tampoco noción alguna de continuidad espacial y temporal. 
Las imágenes y los sonidos realistas que las acompañan están a su merced». (p. 162).

Si bien se admite este predominio del relato oral sobre lo audiovisual, es necesario reconocer que la imagen, además de jugar un papel complementario en relación con la palabra hablada, posibilita la creación de referentes de carácter cultural y sociológico. Jesús García (1995), teórico estudioso de la cultura audiovisual, plantea que desde un nivel iconológico la imagen permite la interpretación sociocultural y caracterizar el contexto. De acuerdo con ello, desde este nivel iconológico, la imagen aporta información sobre cómo es la vida en Belén de los Andaquíes, cómo son sus calles, retrata su cercanía con la selva del Amazonas, documenta a través del video, de la fotografía y de las ilustraciones a sus habitantes actuando tanto en el ámbito doméstico como en los lugares públicos.

Es posible, entonces, afirmar que cuando el relato oral entra en su fase ilimitada surge "la oralidad mestiza”, es decir, la palabra hablada se hibrida, se expande hacia el territorio de la imagen y desde allí, no crea un significado nuevo, sino que se regramaticaliza, reitera su sentido, toma nuevas formas, con lo cual reafirma el enunciado de la palabra y muestra nuevas dimensiones del discurso oral en las que se presenta combinada con la fotografía, con lo audiovisual, con la animación o con otros lenguajes expresivos.

Esta oralidad mestiza también se mezcla con los lenguajes y las formas de producción que trae consigo el ciberespacio. Manuel Ángel Vásquez, catedrático e investigador en temas de comunicación digital, propone insertar el relato oral en el tercer entorno ${ }^{2}$,

2 El filósofo de la ciencia Javier Echeverría plantea la teoría de los tres entornos por los que ha atravesado la humanidad. El primero es la naturaleza, el segundo es el conjunto de aldeas, ciudades y Estados, y el tercero lo constituyen las tecnologías de la comunicación y la información (TIC): «en este nuevo entorno ha surgido y se está desarrollando una nueva modalidad de sociedad, la sociedad de la información, que se superpone a las sociedades rurales, urbanas e industriales» (como se citó en Vásquez, 2014, p. 124). en el ciberespacio, en el campo de las nuevas tecnologías. El resultado, según Vásquez (2014), es una oralidad múltiple, dialogante y multimodal que se adapta a las diferentes lógicas, y formas de escrituras instauradas por los nuevos entornos tecnológicos.

Se podría señalar que en el caso de la EAI, el uso de software que implica el montaje digital y la circulación en plataformas de internet, permite el paso de una oralidad primaria a una oralidad multimodal. En ese sentido, el relato oral que maneja la EAI hace un tránsito hacia un texto múltiple que convoca la participación de otros lenguajes, de otros recursos estéticos y narrativos para que enriquezcan los significados que subyacen en el discurso oral. Vásquez (2014), en su texto, introduce el término de oralidad multimodal o transoralidad:

Defendemos la idea de una tercera oralidad, una oralidad múltiple y diversa, una nueva oralidad rica y fecunda. (...) Oralidad, en cualquier caso, que trasciende los límites de la primera, de la segunda oralidad humana y se transforma en transoralidad, en algo más que oralidad, pues no excluye su convivencia con otras posibilidades comunicativas. (p. 133).

En conclusión, una tercera forma de escribir la nación es a través de una oralidad mestiza. El relato oral de la EAI ha cruzado por el ámbito de la cultura masiva, por el escenario de la producción de video, por el territorio de la imagen y por los tejidos de las nuevas tecnologías de la información. Entonces, la oralidad mestiza nace en medio de estos múltiples cruces y fronteras comunes, el discurso oral de la EAI no pierde su esencia, no se desconecta de la estética y la narrativa local y continúa ligado a las sensibilidades de niños y jóvenes del municipio. La de Belén de los Andaquíes es una oralidad mestiza en la que conviven los conocimientos, los sentires, las resistencias, las formas de vida en el ámbito local, con el campo del ciberespacio, con las nuevas tecnologías, con los aparatos de comunicación y con el mundo global. 


\section{Cuarta clave: la poética de lo casero}

Mi nombre es Marlon Estiven Torres Valencia, soy del Huila, vivo en Belén. El título de mi historia es "Mis vacaciones". Estas fotos fueron tomadas por allá en Santa Rosa, una vereda aquí de Belén. Entonces nos fuimos llegamos a la salida, íbamos en Macondo, nos encontramos gente y animales.

Luis Ángel Barrera, Marlon Steven Torres y Carla Zapata. Ejercicios de narración Karla, Luisito y Marlon.

En la narración de Marlon cada conjunto de fotos es un punto de su camino, cada imagen describe cómo son las veredas, muestra el verdor de los paisajes, revela el carácter campesino de las gentes, pone en escena su cotidianidad ligada a la cría de animales, al cultivo de la tierra. Además, en este video también se pone en escena el sello estético de la EAI, el cual tiene como marca primordial lo casero, lo cercano y lo familiar. Por ello, una cuarta forma de escribir la nación es a través de lo estético, de una poética de lo casero.

El video de Marlon está cruzado por una estética de lo casero, hecha con fragmentos de fotografía familiar, de ilustración con estilo infantil, de imágenes que remiten a lo doméstico y a lo familiar. Esto se ha logrado gracias a la facilidad del video para ser apropiado, por ello se ha convertido en un modo de expresión que propone estéticas "más cercanas, irreverentes, callejeras, cotidianas y comunicativas”. (Rincón, 2006, p. 205).

Los niños de la EAI, a partir de su continua exploración por las posibilidades del lenguaje, han consolidado un sello narrativo y estético acorde a sus formas de ser. Son elementos de este sello la mirada de los niños y las niñas en torno a su vida; la puesta en escena de lo local y lo doméstico; las ilustraciones con rasgos infantiles como una forma de representar la vida cotidiana; el reciclaje de productos de la industria del entretenimiento como recurso narrativo y estético; la búsqueda de diferentes formas de poner en escena los conflictos de los espacios privados. Esta estética de la EAI se construye a partir de la manera de mirar y registrar los espacios, los personajes y los eventos de la vida familiar e íntima. Según la antropóloga cultural María Jesús Buxó (1999), los relatos son una forma de virtualizar la realidad, y con la entrada de equipos tecnológicos, como las cámaras digitales, a los espacios privados cada quien puede construir y comunicar una versión de lo cotidiano. Esto se evidencia en la grabación de rituales como los juegos, las bodas, el turismo y las fiestas populares.

La EAI primero se apropió de la estética de los videos caseros, de la cercanía que generan, del ambiente familiar que transmiten, de las texturas visuales que remiten al hogar, de las charlas que se producen en las familias. Y, segundo, trasladó estas estéticas al terreno de la narración. Es así como lo cercano, lo doméstico, el calor del hogar son usados para contar historias con tono local. Entonces, el video casero se despoja de su naturaleza ritual (bodas, primeras comuniones, matrimonios, graduaciones) y su estética se pone al servicio de los relatos locales contados por los niños.

Hacen parte también de este sello estético de la EAI, "la video expresión", en la cual niños, niñas, adolescentes construyen una mirada propia, una manera de ver y de enfocar la realidad local; así los niños visibilizan sus preocupaciones, sus intereses, sus maneras de ver el mundo y a Belén de los Andaquíes, es decir, la producción de video les permite construir su subjetividad (Rincón, 2006). Otra de las características del sello narrativo de la EAI es el realismo, el cual consiste en no alterar la realidad, no embellecerla, no modificarla ni añadiendo, ni suprimiendo elementos; pasa igual con las personas, se busca representarlas tal y como son en su vida cotidiana, con sus formas de vestir, con sus maneras de ser y con sus modos de habitar los espacios privados y públicos. "Nos ponemos en escena, pero no nos disfrazamos, esa es la apuesta”, asegura Alirio González, gestor de la EAI. 


\section{A modo de conclusión: los sentidos que teje la narración}

Este artículo ha estado movido por la idea de explorar en esas otras formas de escribir la nación y la EAI ha mostrado cuatro claves narrativas: primero, la oralidad como la base de los productos audiovisuales y vehículo para relatar la historia y reafirmar la cultura; segundo, las continuas apropiaciones de los formatos narrativos de la industria audiovisual para contar la cotidianidad; tercero, una oralidad mestiza, producto de la mezcla y fusión continua del relato oral con otros lenguajes, tecnologías y códigos narrativos; cuarto, un sello estético construido a partir de una poética de lo casero, lo cercano y lo familiar.

Esas cuatro formas de relatar la nación que propone la EAI han permitido revelar las regiones, lo cual a su vez puede tener varios sentidos que desbordan el campo de lo narrativo. Mostrar las regiones y sus márgenes es también visibilizar los sujetos que la habitan y su capacidad creativa para reimaginar y transformar su territorio. Buscar las historias que se tejen en las regiones y que van más allá de los límites también es descubrir y poner en circulación los conocimientos, las formas de pensar el mundo y los saberes propios de la cotidianidad y del "sentido común” instalados en la gente. Relatar la región es resignificar lo local, entendido este término como un escenario donde habita la resistencia a ser uniformado, una trinchera para oponerse al despojo de la diferencia y una oportunidad para distinguirse de los demás, contar lo local es desglobalizar la homogeneidad y globalizar el derecho a ser diferentes. Mostrar el mundo que se forja en los límites también significa entender que hoy el país se hace a partir de múltiples fragmentos en donde se funden la cultura oral atada a la memoria campesina, los saberes audiovisuales cercanos a las nuevas generaciones, la música popular ligada a los sentires colectivos, las experiencias tejidas por los niños en su territorio y las estéticas propias de la cultura digital.

\section{Referencias}

Amar, A. (2000). Juegos de seducción y traición. Literatura y cultura de masas. Buenos Aires: Beatriz Bitervo Editora.

Barrera, L., Torres, M., y Zapata, C. (2009). Ejercicios de narración Karla, Luisito y Marlon [Video]. Recuperado de https://www. youtube.com/watch?v=PKXKt0874RQ\&t=368s

Bhabha, H. (2010). Nación y narración entre la ilusión de una identidad y las diferencias culturales. Buenos Aires: Siglo xxi Editores.

Buxó, M., y De Miguel, J. (1999). De la investigación audiovisual. Fotografía, cine, video, televisión. Barcelona: Ediciones Proyecto A.

Capera, J., y González, M. (2007). Papá es una madre [Video]. Recuperado de https://www. youtube. $. c 0 m /$ watch $? \mathrm{v}=8 \mathrm{~g} 8 \mathrm{iaRQPAHc} \& \mathrm{t}=2 \mathrm{~s}$

Castro, S. (1997). "Los vecindarios de la ciudad letrada: variaciones filosóficas de un tema de Ángel Rama”. En M. Moraña (Ed.), Ángel Rama y los estudios latinoamericanos (pp. 123-136). Pitssburgh: Instituto Internacional de Literatura Iberoamericana.

Chion, M. (1990). La audiovisión. Introducción a un análisis conjunto de la imagen y el sonido. Barcelona: Paidós.

Cruz, P. (2005). "El arte en su fase poscrítica: de la ontología a la cultura visual”. En J. Brea (Ed.), Estudios visuales. La epistemología de la visualidad en la era de la globalización (pp. 91-104). Madrid: Akal ediciones.

De Certeau, M. (2000). La invención de lo cotidiano 1. Las artes del hacer. México D. F.: Universidad Iberoamericana. Instituto Tecnológico de Estudios Superiores de Occidente. 
EAI. (2009). Yo también fui desplazado [Video].

Recuperado de https://www.youtube.com/ watch?v=kptgn13i1cE

EAI. (2008). Futuro en Belén de los Andaquíes

[Video]. Recuperado de https://www. youtube.com/watch?v=J9bog2NxBQE\&t=12s

EAI. (2008). El último andaquí [Video].

Recuperado de https://www.youtube.com/ watch?v=wHAcLyy9buk\&t=13s

EAI. (2007). El corrido del gordo [Video].

Recuperado de https://www.youtube.com/ watch?v=xH02S2JGW5o\&t=11s

Silva, M. (2007). La finca de mi abuelo [Video]. Recuperado de https://www.youtube.com/ watch?v=CBrCe7EwBP4\&t=2s

García, J. (1995). La imagen narrativa. Madrid: Editorial Paraninfo.

Martín Barbero, J. (2003). "Desafíos de lo popular a la razón dualista”. En J. Martín Barbero (Ed.), Oficio de cartógrafo. Travesías latinoamericanas de la comunicación en la cultura (pp. 108-165). México D.F.: Fondo de Cultura Económica.
Martín Barbero, J. (2001). "Colombia: ausencia de relato y desubicación de lo nacional”. En J. Martín Barbero (Ed.), Cuadernos de nación. Imaginarios de nación: pensar en medio de la tormenta (pp. 17-30). Bogotá: Ministerio de Cultura.

Rama, A. (1998). La ciudad letrada. Montevideo: Ediciones Arca.

Rincón, O. (2006). Narrativas mediáticas, O cómo se cuenta la sociedad del entretenimiento. Barcelona: Editorial Gedisa.

Vásquez, M. (2014). "La oralidad en el tercer entorno. Oralidad, comunicación audiovisual y comunicación digital”. En M. Rodríguez \& R. Pinilla (Ed.), Oralidades. Saberes y experiencias de investigación en red (pp. 123-134) Bogotá: UD Editorial. Universidad Distrital Francisco José de Caldas.

Zambrano, J. (2015). El dragón [Video]. Recuperado de https://www.youtube.com/ watch?v=4qqWjRfo43Y\&t=19s 